\title{
ARS LONGA, BUT IS THE INDEX ADEQUATE?
}

Five contemporary Canadian indexes

Biographical Index to Victor Lauriston's Romantic Kent, compiled by Mabel Barnwell and Bernice Peacock. Chatham, Ont.: Mercury Press, 1973, 1967. 43 p. $\$ 2.00$

Canadian Essay and Literature Index, 1973, compiled and edited by Andrew D. Armitage and Nancy Tudor. Toronto: University of Toronto Press, 1975. $\$ 27.50$

The Canadian Historical Review Index, Volumes XXXI-LI, 1950-70 /by Audrey Douglas/ Toronto: University of Toronto Press, 1974. viii, 219 p. $\$ 25.00$

Index to the Publications of the Ontario Historical Society, 1899-1972/by Hilary Bates and Robert Sherman/ Toronto: Ontario Historical Society, 1974. $\mathrm{x}, 175$ p. $\$ 3.25$

Revised and Updated Index to the Periodical Canadian Literature, Nos. 1-62, compiled by Glenn Clever. Ottawa: Golden Dog Press, 1975. 195 p. $\$ 10.50$

The art of indexing in Canada has not been lost - yet. It is simply having difficulty in surmounting the increasing rubble of lists of one kind or another which are foisted on the public in the guise of indexes. Until recently it seemed safe to assume that any monograph of sufficient scholarship would have an index as a necessary appendage, just as every periodical of moderate calibre or interest would either be self-indexed, caught up in a general and/or special subject index, or all three. Mildly put, this has not been, and is not, the case. The difference appears to be that the public has, at last, become aware of the lacunae and is increasingly critical of the half-way measures being used to fill them. Justifiably so, considering the average price of the items herein reviewed is nearly $\$ 14.00$ in each case. Even if the view is taken that such publications will receive institutional support in terms of acquisition, if not support from individual members of the public, only a minute and very selective support will be possible given the enormous number of individual indexes which are necessary.

This present day awareness, primarily with regard to periodical indexes, has been expressed in terms of surveys conducted by the Index Committee of the Bibliographical Society of Canada, ${ }^{1}$ and is being expressed in the study of a special Review Committee for the Canadian Periodical Index of the Canadian

1 "Indexing in Canada: Local Indexing and Commercial Services", by Peter Greig and Joyce Tracy. The Indexer, v. 8, no. 2, October 1972, p. 88-93

"Book Indexing in Canada", by Peter Greig. The Indexer, v. 8, no. 3, April 1973, p. 164 171 
Library Association, ${ }^{2}$ and by a survey of commercial Canadian abstracting and indexing services by the newly established Committee on Bibliographical Services for Canada of the National Library Advisory Board. ${ }^{3}$ The increased demand for adequate periodical indexing services may also be seen in the recent publication of the Canadian Business Periodical Index by Micromedia Limited in Toronto.

Despite the ever-inherent dangers of over-surveying and over-committeeing, it does seem possible to legislate some beneficial changes in the field of periodical indexing. Monographic materials, by their very nature, are less amenable to postpublication correction; once an item is published without an index, or with an inadequate one, the opportunity for remedying this through a subsequent edition or a re-issue is slight. One solution, although only marginally 'better than nothing', has been to publish an index separately as with the Biographical Index to Victor Lauriston's Romantic Kent reviewed below. The real solution, more difficult to achieve, would be to convince Canadian publishers of the necessity of including an adequate index in all non-fictional works issued by their respective firms. It is the publisher alone who has to face the increased costliness of book production and who must be coerced, rather than the author or his reading public. Here again, segements of the public, as evidenced by past reviews in the Papers of the Bibliographical Society of Canada and in other reviewing media, are becoming increasingly critical of existing back-of-the-book indexes and, indeed, of the selective technique of indexing currently practised by book publishers in Canada and abroad.

This lengthy preamble appears necessary, since the five titles to be reviewed illustrate so aptly most of the faults of the contemporary index in Canada. By way of a preliminary summary these faults include: over-sectionalization; inadequate or inconsistent subject access; absence of cross references; poor typography, and unsatisfactory punctuation, spacing and indention.

H.B. Wheatley's authoritative statement that "an index should be one and indivisible, and should not be broken up into several alphabets"4 has more often been honoured in theory than in practice. As early as 1905 Martha Thorne Wheeler, author of a manual on indexing, noted a Canadian work which not only disregarded Wheatley's specific advice, but did so in some twenty-three sections. 5 None of the indexes under review are quite so lavish, although only the

2 The Canadian Library Association conducted a survey of Canadian Periodical Index subscribers and the CLA membership to determine both short and long term objectives for the Canadian Periodical Index. The survey was distributed in August 1975 and a final report was prepared by the Review Committee in February 1976.

3 The Committee on Bibliographical Services for Canada was established in May 1975. The survey on Canadian abstracting and indexing services was distributed in February 1976 and a report is in preparation.

${ }^{4}$ How to Make an Index, by H.B. Wheatley, London: Elliot Stock, 1902, p. 69

5 Indexing: Principles, Rules and Examples, by Martha Thorne Wheeler. 5th ed. Albany: New York State Library, 1968, 1957, p. 9-10

The reference is to Canada, an Encyclopedia of the Country which was "provided with a slender index volume divided into no less than thirty-three sections, eleven of which are arranged alphabetically, the remaining twelve being contents grouped under class headings and arranged in order of occurrence." 
Biographical Index to Victor Lauriston's Romantic Kent and the Revised and Updated Index to the Periodical Canadian Literature, Nos. 1-62 are confined to a single index. The Index to the Publications of the Ontario Historical Society, 1899-1972 is in three parts (chronological table of contents, author index, and subject index), the Canadian Essay and Literature Index, 1973 is in five parts (essays, book reviews, poems, plays and short stories), and the Canadian Historical Review Index, Volumes XXXI-LI, 1950-70 is clearly the worst offender with seven parts (articles by author, articles by subject/title, review articles by author, review articles by subject, book reviews by author, book reviews by reviewer, and miscellaneous). Since both the Canadian Historical Review Index and the Canadian Essay and Literature Index are the most heavily sectionalized, they will repay closer examination to see if such a complex structure is necessary.

The present volume of the Canadian Historical Review Index, covering a twenty year period, is the fourth to be published by the University of Toronto Press since the journal's inception. The introductions to the earlier index volumes, each covering only a decade, indicate that the compiler-indexers considered themselves to be working in the tradition of the even earlier indexes to the Review of Historical Publications Relating to Canada. As such, one of the main functions was to list those publications listed under "Recent Publications Relating to Canada", as the section came to be termed in the Canadian Historical Review. The present index, arguing that the many bibliographies of Canadiana produced since 1950 have nullified any need for a close analysis of this section, has omitted the materials listed under "Recent Publications Relating to Canada" altogether and confined itself solely to the articles, reviews, notes and comments produced for the journal. In doing so the indexer has not only broken with his predecessors' works, but also weakened the total context, lessening the value of the overall index as a general guide to Canadian historiography.

The first three indexes to the Canadian Historical Review, ranging from a 284 page index to the first ten volumes to over 400 pages for each compilation for the next two decades, were each divided into two sections comprising authors and subjects. The decision to subdivide the index into seven parts for the period 1950 to 1970 may have been influenced by, although it is certainly less effective than, René Hardy's multi-sectional Canadian Historical Review, index des articles et des comptes rendus de volumes, 1950-1964 published in 1969 by the Université Laval. The divisions created in the 1950-70 Canadian Historical Review Index are arbitrary and artificial. The decision to divide them in this way is dictated initially by a strict adherence to the forms of the material included in the Canadian Historical Review: articles, review articles, book reviews and miscellaneous notes entered under various uniform headings. Even given that the volume is photo-offset from typewritten copy, it displays an unimaginative use of the typographical means at the compiler's disposal. The number of alphabets generated could be reduced by some sixty percent, by the use of mnemonics or full caps to distinguish authors from subjects, or authors from reviewers; while the alphabetized arrangement of the relevent uniform headings under "Miscellaneous" would have prevented any need for four random sub-alphabets.

The essential factor from the user's point of view is whether this generous division of the material is going to facilitate the use of the index. To search out all the reference works or notes by or about F.H. Underhill, the diligent user 
must look under articles by author and reviewer and, should this same pattern of extra-alphabetization prevail for the next index, it is only a matter of time before Underhill occurs as a subentry in one or other of the miscellaneous divisions. By creating so many alphabets the indexer may have facilitated his work, but only at the expense of the user's time and ease in consulting the index.

The Canadian Essay and Literature Index, unlike the Canadian Historical Review Index, is not a continuation of an existing service. The obvious inspiration, although disregarded in terms of a close model, is the Essay and General Literature Index. In providing access to the contents of some ninety-one monographic collections or anthologies and thirty-eight Canadian magazines, the Canadian Essay and Literature Index's aim has been to complement, rather than duplicate, existing services such as the Canadian Periodical Index. While the utility of such a reference service remains unquestioned, one wonders at the relationship between this particular service and the "Canadian Essays and Collections Index", recently completed by the Information Services Section of the Canadian Library Association but not yet published.

The five part division of the Canadian Essay and Literature Index is based on the form of the material being indexed. Since this content, aside from the essays, is predominantly literary, it is natural to find sections devoted to poems, plays and short stories. The rationale for a section devoted to book reviews is not immediately obvious, until it is realized that the reviews are of book-length materials which do not appear elsewhere in the index. Unlike the Canadian Historical Review Index, each section of the Canadian Essay and Literature Index forms an integrated alphabet of author, subject and title entries typographically distinguished from each other. An exception is made in the book review section, in which access is provided solely through the authors and titles of the books reviewed. Invariably the author entry in each section is the main entry to which reference must be made from the title and subject secondary entries for the full bibliographical details. This two-step process may prove onerous for the user in the event of a search involving a large number of secondary entries. On the whole, the prospective user will not be inconvenienced by the sectional arrangement and separate alphabets of the Canadian Essay and Literature Index, particularly if (s)he is working within a specific literary form. It is less easy to locate immediately everything that an individual author may have written if more than one form is involved.

Generally speaking, and although both the Canadian Historical Review Index and the Canadian Essay and Literature Index are products of the University of Toronto Press, the latter is easily the more typographically distinguished. There is an imaginative use of a variety of type faces involving italic, roman, bold face and full caps which goes beyond the typography used in any of the other four indexes under review. These type faces aid to distinguish author, subject, and both book and article title entries. Unfortunately, in common with much of the University of Toronto Press' computer typesetting, this effect is marred by the lack of indention and inadequate spacing between entries.

The Index to Publications of the Ontario Historical Society, 1899-1972 represents the first comprehensive attempt to provide an overall index to the Society's works, even though lesser, more specialized indexes have appeared from time to time. Although the index comprises three parts, the division is 
neither excessive nor illogical. The first section, being a chronological table of contents, is incompatible in terms of integration with the separate author and subject indexes which follow. While, through the use of full caps for all subject main entries, it would have been possible to integrate the author and subject parts, their division should not assume too great an inconvenience for the user. Given, as with the Canadian Historical Review Index, the necessary limitations of producing finished copy by means of photo-offset from a typewritten original, the end result is highly legible through intelligent spacing and indention, and the provision of adequate margins.

The subject analysis displayed by the indexes under review, with the exception of the Canadian Essay and Literature Index and the Index to the Publications of the Ontario Historical Society, is unsatisfactory. The Biographical Index to Victor Lauriston's Romantic Kent must necessarily be excluded from such a criticism, since it is only an index nominem, and not a glossarial index as the title might imply.

Clever's Revised and Updated Index to the Periodical Canadian Literature, Nos. 1-62 represents little improvement over the earlier work published in $1973 .{ }^{6}$ Both editions have been reproduced by photo-offset, from a poorly laid out typewritten copy. The indention is clear, although some of the generous space allotted in this regard might have been better used to increase the gutter margin. Although Canadian Literature is devoted largely to literary criticism, the compiler has added a smattering of general subject entries to what is essentially an index of names of authors, reviewers, and authors as subjects. The general subject entries are frequently difficult to distinguish from the occasional title entry, eg. "Canadian Annual Review", as the latter is not underlined. The subject terminology is loosely catchword in origin, although the application tends to be clumsy and verbose ("Immigrant Theme in Canadian Literature"). The faulty analysis is compounded by inconsistencies, such as the article on private presses in Vancouver which appears under "Media" and "Vancouver", but not under the equally relevant "Little Presses" and/or "Printing". Clever has raised the technique of selective indexing from an economic necessity to a virtue, terming his approach the principle of "reasonable inclusiveness"; unfortunately, the result does not appear to bear out his theory with any success.

Researchers are fortunate that the Canadian Periodical Index continues to provide consistent if limited coverage of both Canadian Literature and the Canadian Historical Review. The latter compilation, for the period from 1950 to 1970 , has not been content to follow the exhaustive and detailed model provided by its predecessors. In place of a single subject index, the present volume supplies a subject-title index to twenty years of scholarly historical articles in as many pages, as well as a two-page 'subject' index to the review articles. The subjecttitle index to the articles depends on an elementary use of permuted titles, bringing an ad hoc key word to the fore in lieu of any attempt to analyze properly the subjects involved. Thus, Abella's article on 'The "Sydenham Election" of 1841 " is arranged so that both "Sydenham" and "Election" will allow subject access. Adair's 'The French-Canadian Seigneury' appears to be provided

6 An Index to the Contents of Canadian Literature, Nos. 1-50, with an Addendum for Nos. 51-54, by Glenn Clever, et al. Ottawa: Golden Dog Press, 1973. 170 p. 
with only title access, with no reference to the subject of the seigneurial system. The review articles are not even vouchsafed such summary subject analysis; rather, they have been listed in a cursory manner under broad geographical headings (Canada, Europe and Asia, United Kingdom, U.S.A.), with a catch-all additional heading, "Miscellaneous". In effect, this most recent index to the Canadian Historical Review does little more than provide an up-to-date example of the faults which Wheeler noted seventy years ago, in the index to Canada, an Encyclopedia to the Country. ${ }^{4}$ The fact that this index has been produced and considered worthy of publication by the University of Toronto Press, the most prestigious university press in Canada, only heightens the need for more vocal public criticism.

The subject access in both the Canadian Essay and Literature Index and the Index to the Publications of the Ontario Historical Society seems adequate and consistent. The number of subject access points for an individual article in the latter index averages three to four entries, with more if necessary. The compilers of the Index to the Publications of the Ontario Historical Society have, like Clever, been constrained to adopt the practice of selective indexing inasmuch as the "degree of specificity of this index was determined by time and space". The results appear to be not only consistent in themselves but, equally important, appropriate to the needs of prospective users. The subject indexing in the Canadian Essay and Literature Index appears at first sight to be something of an anomaly, since the bulk of the materials indexed are literary by nature. It is unfortunate, though understandable, that the book reviews have no subject access; but this is compensated for by the new subject approach, which can be made to such literary forms as poems, plays and short stories. The only problem with the subject entries, as with the title entries, in the Canadian Essay and Literature Index is that the full bibliographical citation is given only once, under the appropriate author's name in each section. In the case of a periodical item, this requires a second step to obtain the needed bibliographical information. Items from anthologies and collections require yet a further step, to the list of books indexed at the end of the index, since the information under the author entry in any given section only identifies the author and/or title of the relevant anthology or collection.

A niggardly use of cross references has been uniform in all five indexes under review. Despite their restraint, both the Canadian Essay and Literature Index and the Index to the Publications of the Ontario Historical Society appear to have used both see and see also references correctly and to good effect. Clever's Revised and Updated Index to the Periodical Canadian Literature employs the abbreviation 'cf.' to indicate a cross reference. This is, in fact, an incorrect usage since, 'cf.' ('confer'), means compare, implying that a comparison of material is to be made and not a directional reference. There is an additional imprecision when 'cf.' is used to direct a reader from a pseudonym to a real name - what is there to compare in going from Grey Owl to Archie Belaney? A further lack of care is demonstrated in this same reference; the indexer, while he should use an index language based on that of the document, should be meticulous in supplying the full name, when possible, of individuals referred to in the text. In this case the entry more properly should have been "Belaney, Archibald Stansfeld". The entry 'Beaverbrook, Lord' is another instance in which an unwary reader might 
be misled, without a joint use of the proper cross reference and a full name entry. The use of the full title, 'Beaverbrook, William Maxwell Aitken, 1st baron', would have avoided any possible confusion with the son who now enjoys the title, and a cross reference from 'Aitken' is also in order.

Little reference has, as yet, been made to the Biographical Index to Victor Lauriston's Romantic Kent. This omission is not intentional, although it may be inferred that this particular work stands apart somewhat from the other indexes under review. The publication of indexes separately from the monographs they describe is a regrettable practice, but generally indicates a necessary, if unhappy, solution. Mesdames Barnwell and Peacock are to be complimented for their initiative in indexing Lauriston's work, and it is only unfortunate that they were not able to go further in their work. Romantic Kent was subsequently reprinted, and it seems shortsighted on the part of the publisher not to have incorporated the present index at that time. The copy of the index being reviewed is, in fact, a reprint in which a number of typographical errors remain from the initial impression in 1967.

It is interesting to note that three of the indexes are reproduced from typewritten copy. This is regrettable to a degree, since the average typewriter type face, without careful spacing, tends to verge on the illegible. A fair amount of variation in type face can be introduced through a judicious use of an IBM Selectric; the indexes to the Canadian Historical Review and Canadian Literature would have been greatly improved if such a machine had been employed. In addition to both adequate spacing and varied typography, an essential key to legibility in index format is the indention. The user should not be expected to read the index; the purpose of the index is to guide the user as quickly and efficiently as possible to the relevant material in the text. Indention, aside from its role in preventing confusion between access points, allows the user to scan a column to determine if there is a reference to the required information. The increased use of computer typesetting, and a lack of definite policy with regard to the typographical style in indexing, mars the output of many publishers today and, in particular, that of the University of Toronto Press. Currently, Information Canada is involved in producing a revision of the Canadian Government Style Manual which will contain a much expanded chapter on index-making. Mr. Royd Beamish, who has been responsible for this revision, has incorporated into this chapter the statement that, regardless of whether an indented style or a paragraph style is employed as the index style, a basic indention of one em must be allowed following the first line of the entry. In the case of the indented style, subsequent lines or subentries would have to be indented one em further. In terms of these typographical-format requirements, the Index to the Publications of the Ontario Historical Society comes closest to fulfilling the theoretical model; it is all the more unfortunate that this particular work could not be enhanced by a greater variation in type faces.

There remains one final aspect on which the five indexes under review should be examined: each index, in its own way, represents a variation of the practice of selective indexing. Selective indexing, as was observed in the introduction to the Index to the Publications of the Ontario Historical Society, is "determined by factors of time and space!" Even more relevant, from the publishers' point of view, is the question of money. Back-of-the-book indexes are restricted not only 
by space (the number of pages allotted for the index) but even more so by money (the cost of adding another quire to the work to accommodate a larger, more comprehensive index). While the five indexes under review would naturally have been affected by cost considerations, the degree of comprehensibility could have theoretically been much greater since there was no pressing need to fit any one of them into an existing space.

Despite this freedom, each compiler felt constrained to assemble his materials on a selective basis. The Biographical Index to Victor Lauriston's Romantic Kent was restricted to personal names, with a very slight admixture of place names composed in part of personal names. The Canadian Essay and Literature Index was not so much selective in what was indexed as in the amount of information provided; a distinction was established between a principal entry, with full bibliographical information, and a secondary entry which included a reference to the main, author, entry. The selective decision incorporated into the production of the Canadian Historical Review Index was to omit the detailed analysis of "Publications Relating to Canada". While this decision certainly reduced the amount of work and the bulk of the index, it is all the more unfortunate that the remainder of the index could not have been undertaken in a more professional spirit and style. The Index to the Publications of the Ontario Historical Society provides the best model to follow in all respects. The introduction provides a coherent and clear statement of the selective process in preparing the index - which the index then proceeds to demonstrate in a consistent manner. The Revised and Updated Index to the Periodical Canadian Literature, despite its "principle of reasonable inclusiveness", tends to show the reverse side of the coin. The end result might have been better if Clever had concentrated on an integrated alphabet of authors of articles, authors as subjects of articles, titles of articles, and book reviews by authors and titles of books reviewed and names of reviewers. The inconsistency in the subject treatment is the major fault which decreases the value of the work.

\section{Peter E. Greig}

\section{BOOKS IN REVIEW}

We earnestly invite our readers to propose suitable titles for review here. Works of bibliographical interest for review are welcomed from publishers by the Review Editor. Whenever possible, reviews will be printed in the language of the book being reviewed: French or English. We are always pleased to hear from subject specialists who are willing to review new publications in their field, for we are particularly concerned that our reviews shall be authoritative. The Review Editor also welcomes progress reports on long-term bibliographical projects in preparation for the press. An annual publication such as this cannot maintain current information on short-term projects, so progress reports on these will now be published in the Society's Bulletin; they should be addressed to Ms. Elizabeth Hulse, Thomas Fisher Rare Book Library, University of Toronto, Toronto M5S 1A5. I must thank our reviewers for their contributions to the Papers, but opinions expressed in these reviews are not necessarily those of the Bibliographical Society of Canada. 